\title{
Unusual presentation of cholangiocarcinoma
}

\author{
J. H. MARIGOLD* \\ B.M., M.R.C.P. \\ L. W. L. HORTON† \\ M.R.C.P., M.R.C.Path. \\ R. P. H. THOMPSON* \\ D.M., F.R.C.P. \\ *Gastrointestinal Laboratory, Rayne Institute, and †Department of Surgical Pathology, \\ St Thomas' Hospital, London
}

\begin{abstract}
Summary
A patient who presented with dysphagia was found to have a cholangiocarcinoma, with metastases in the para-oesophageal lymph nodes. Although dysphagia has been described as a presenting feature of some metastatic carcinomas, to the authors' knowledge, there have been no reports of it as a presenting symptom of a cholangiocarcinoma.
\end{abstract}

\section{Case report}

A 57-year-old man presented with dysphagia for solid foods, right shoulder-tip pain, and rapid weight loss. A barium swallow examination showed the oesophagus to be dilated above a smooth stricture $1.5 \mathrm{~cm}$ from the diaphragm. Upper gastrointestinal endoscopy demonstrated a smooth tight stricture at the gastro-oesophageal junction; biopsy specimens and brushings showed no evidence of malignancy.

He suddenly collapsed at home a few days later. On admission to hospital he was drowsy, with hypotension and marked peripheral vasoconstriction; there was an epigastric mass adjacent to an enlarged liver. Initial investigations showed a metabolic acidosis and a coin lesion in the right upper zone on chest X-ray. An ultrasound examination suggested focal hepatic defects and an epigastric mass. Although disseminated malignancy was likely, no histological diagnosis had been made, and he was treated with intravenous fluids and antibiotics. However, he developed abdominal tenderness and ascites. At laparotomy the liver was found to be studded with tumour nodules; cytology of a smear of one of these nodules showed anaplastic carcinoma. The patient died on the 5th postoperative day.

Post-mortem examination revealed a haemorrhagic nodular mass of tumour on the inferior surface of the liver, with similar tumour around the diaphragmatic hiatus markedly constricting the oesophagus and inferior vena cava, and a solitary tumour nodule on the right parietal pleura. His tology of the liver tumour showed a moderately well differentiated mucus-secreting adenocarcinom in a dense fibrous stroma with the appearances of a cholangiocarcinoma. Metastases in the pleuraf nodule and diaphragmatic nodes were confirmed There was no invasion of the oesophageal wall by tumour and no primary site other than the liver faso found.

\section{Discussion}

Dysphagia due to compression of the oesophagus by tumour spreading directly from adjacent struce tures is well recognized, but compression caused by local lymph node involvement from a distant pri mary carcinoma is less common. Intraluminal oesoô phageal metastases from a distant primary carcinoma are very rare (Savary and Miller, 1978).

In a monograph describing unusual clinical features of liver cell carcinomas, Leon-Sotomayo and Moore (1967) did not include dysphagia as presenting symptom; however, they did refer to the report of Sohn, Valensi and Bryk (1965), whis described a patient with an intraluminal oesophagea $\$$ metastasis from a hepatocellular carcinoma, in whom dysphagia developed only 8 months after present ation. Dysphagia as the presenting symptom of prostatic carcinoma has also been reported (Gross and Freedman, 1942).

In a retrospective post-mortem series of $59 \%$ patients dying of cancer, Toreson (1944) found $2 \mathscr{W}$ with oesophageal metastases. Twelve of these hafj had dysphagia at some stage of their illness, but in only 3 were the metastases from distant primary sites. Dysphagia as a presenting feature of metastatio carcinoma is therefore rare and, to the authors? knowledge, there has been no previous report of it a a presenting symptom of a cholangiocarcinoma. 


\section{References}

Gross, P. \& Freedman, L.J. (1942) Obstructing secondary carcinoma of the esophagus. Archives of Pathology, 33, 361.

LeON-Sotomayor, L. \& Moore, V.A. (1967) Unusual Clinical Features of Cirrhosis and Primary Liver Cell Carcinoma, p. 90. Charles C. Thomas, Springfield, Illinois, U.S.A.
SAVARY, M. \& Miller, G. (1978) The Oesophagus: Handbook and Atlas of Endoscopy, p. 229. Verlag Gassmann AG, Switzerland.

SoHn, D., VAlensi, Q. \& BRYK, D. (1965) Hepatoma metastasising to the esophagus. Journal of the American Medical Association, 194, 910.

TORESON, W.E. (1944) Secondary carcinoma of the esophagus as a cause of dysphagia. Archives of Pathology, 38, 82. 